Published in Personality and individual differences, 1 April 2017, vol. 108, pp. 154-157 which should be cited to refer to this work

\title{
Procrastination, personality traits, and academic performance: When active and passive procrastination tell a different story.
}

\begin{abstract}
Our study examines the nomological network of active procrastination in comparison with passive procrastination. In particular, we examine the effects of the five factor model with the aim to understand which personality traits predict academic procrastination. We also test the effect of passive and active procrastination on academic performance to study the unique contribution of each type of procrastination. In a sample of 178 university students in Switzerland, we find that extraversion and neuroticism are related to active procrastination. Furthermore, active procrastination predicts GPA to a much greater extent than the five factor model and passive procrastination.
\end{abstract}

Keywords: Personality; Five factor model; Passive Procrastination; Active Procrastination; Academic performance 


\section{Introduction}

Procrastination has been considered a dysfunctional behavior or an irrational delay of behavior (Ellis \& Knaus, 1977; Silver \& Sabini, 1981) associated with negative outcomes. It has been defined as a "voluntarily delay of an intended course of action despite expecting to be worse off for the delay” (Steel, 2007, p.66). In particular, academic procrastination appears to concern over 50\% of college students (Solomon \& Rothblum, 1984) and has negative consequences such as cheating (Roig \& DeTommaso, 1995) and low academic performance measured by GPA, assignment grades, quiz scores, and course grades (Kim \& Seo, 2015; Steel, Brothen, \& Wambach, 2001).

Counterbalancing the negative view that has dominated this field of research, Choi and Moran (2009) developed the construct of “active procrastination.” The latter describes the behavioral characteristic that includes an individual's preference for time pressure, cognitive decision to procrastinate, capacity to meet deadlines, and ability to achieve satisfactory outcomes. From this perspective, active procrastination (vs. "passive procrastination” which denotes the undesirable aspect of procrastination) is a functional delay whereby an individual intentionally postpones his action and benefits from it (Alexander \& Onwuegbuzie, 2007; Bernstein, 1998; Chu \& Choi, 2005; Howell \& Watson, 2007).

While some researchers have argued that purposeful delay is not procrastination at all (see for instance Pychyl, 2009), from a historical perspective the earlier meanings of procrastination reflected notions of sagacious delay or wisely chosen restraint (DeSimone, 1993). In fact, procrastination has been a prevalent phenomenon in history that was interpreted as a wise course of (in)action until the industrial revolution where it gained its negative connotation (Ferrari, Johnson, \& McCown, 1995).

With the aim to provide empirical evidence of the unique contribution of each type of procrastination, we examine the nomological network of active procrastination in comparison with passive procrastination in an academic setting (see figure 1). We test if different 
personality traits predict different types of procrastination by using the five factor model (or the big five) whereby individual differences in terms of personality can be captured through five main traits (McCrae \& Costa, 1997). These are: Openness to experience (appreciating divergent thinking), conscientiousness (associated with competence and self-discipline), extraversion (tendency to be energized by social interactions and diverse activities), agreeableness (characterized by altruism and a cooperative nature), and neuroticism (tendency to experience negative emotions such as depression). In addition, we also test the relationship of passive and active procrastination and academic performance to study the effect of each type of procrastination on the outcome variable.

2. Methods

\subsection{Sample and Procedure}

Our sample consists of students at a hospitality management school in Switzerland. In 2013, 290 students completed a personality questionnaire as part of an assignment in an Organizational Behavior course. In 2015, the same students were asked to fill out the procrastination surveys. In total, 178 participants completed all questionnaires (mean age: $22.62(S D=1.59) ; 61.8 \%$ of women $)$. All participants were full-time students with an average university attendance of two years and two semesters of compulsory internship. The distribution of the participants' ethnicity is as follows: European (81\%), Asian (11.2\%), North American (3.3\%), Arabic (2.2\%), South American (1.7\%), and Oceania (0.6\%).

\subsection{Measures}

Big five personality factors. We used the 300-item International Personality Item Pool (IPIP-300) developed by Goldberg (1999) to measure the big five as this instrument possesses adequate psychometric characteristics (Goldberg et al., 2006). Participants used a 5-point scale ranging from 1 (very inaccurate) to 5 (very accurate) to respond to the items. 
Reliabilities for the five traits range from .87 to .95 and reliabilities for the 30 facets of the personality dimensions range from .59 to .90 .

Passive procrastination. We used the 16-item Tuckman Procrastination Scale developed by Tuckman (1991) to measure passive procrastination. Participants responded on a 4- point scale ranging from 1 (that's not me, for sure) to 4 (that's me, for sure). Sample items include: “I needlessly delay finishing jobs, even when they are important”, “I manage to find an excuse for not doing something”, and “I am an incurable time waster.” Reliability for this scale is .89 .

Active procrastination. We used the 16-item Active Procrastination Scale developed by Choi and Moran (2009) to measure passive procrastination. Participants responded on a 7-point scale ranging from 1 (not at all true) to 7 (very true). The four dimensions of active procrastination are: ability to achieve satisfactory outcomes (e.g., "I achieve better results if I complete a task at a slower pace, well ahead of a deadline” (reverse coded)); time pressure (e.g., “I'm frustrated when I have to rush to meet deadlines” (reverse coded)); cognitive decision to procrastinate (e.g., “To use my time more efficiently, I deliberately postpone some tasks.”) and capacity to meet deadlines (e.g., "I often start things at the last minute and find it difficult to complete them on time” (reverse coded)). Reliability for this scale is .77 and ranges from .76 to .86 for the four dimensions.

Academic performance. We used the students’ grade point averages (GPA) obtained from the administration department of the institution to measure academic performance. Control variables. We controlled for gender ( $1=$ female; $0=$ male $)$ and age.

\section{Results and discussion}

Table 1 presents the descriptive statistics and bivariate correlations between the main variables while Table 2 displays an in-depth analysis of the personality facets in relation to active procrastination. First, in regards to traits and procrastination, our results show that 
extraversion, agreeableness, and conscientiousness negatively correlate with passive procrastination. Extraversion refers to individuals’ general tendency to approach social situations. Extraverts might not procrastinate because they are active and assertive individuals who enjoy engaging in multiple activities at a fast-pace rhythm and to take charge of the situation. Yet, our findings also demonstrate that this disposition is related to active procrastination. This implies that when such individuals engage in procrastination they do so deliberately with the aim to be more efficient.

Agreeableness alludes to the ability to relate to others and is, generally, a character trait shared by individuals who are considerate and cooperative. Agreeable students might not engage in passive procrastination because they are mindful of others who might be dependent on the tasks they need to complete.

In line with previous research, conscientiousness is negatively associated with (passive) procrastination (Johnson \& Bloom, 1995; Schouwenburg \& Lay, 1995; Watson, 2001). Students who score high in this trait might not procrastinate as they are dependable and goal-oriented individuals driven by what they set to accomplish. Yet, we also found that conscientiousness strongly correlates to the sub dimension 'ability to meet deadlines' implying that voluntary delay is displayed as conscientious students expect to attain their objectives.

Our study also shows that neuroticism is related to the two types of procrastination. In support of past research, which demonstrates that neuroticism moderately correlates with procrastination (Johnson \& Bloom, 1995; Lay, 1995; Milgram, Batori, \& Mowrer, 1993), we found that emotionally unstable students tend to procrastinate academically. Interestingly, our results demonstrate that students who score high in neuroticism do not engage in active procrastination. An explanation might be that this type of student does not deliberately delay an activity as this might lead to a high level of stress that might have been already generated 
by passive procrastination. Overall, active procrastination and passive procrastination relate differently to the big five personality dimensions.

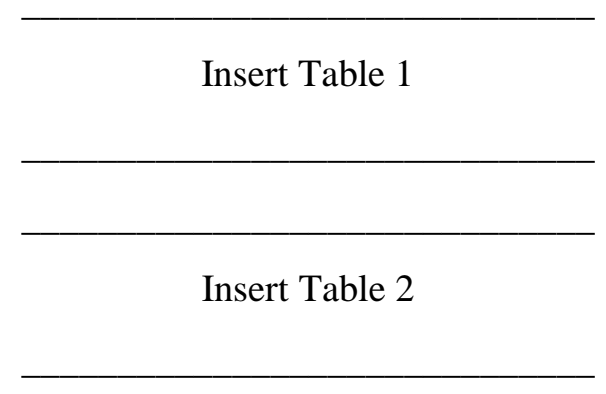

We also conducted a hierarchical regression analysis to test whether both types of procrastination add value in the prediction of GPA. We first entered age and gender, then the big five traits, followed by passive procrastination, and finally active procrastination. As shown in Table 3, gender and age have no impact on GPA. Conscientiousness and openness to experience offered incremental validity; conscientiousness is related positively and openness to experience is related negatively to GPA. These results are interesting because previous research has shown that both traits are positively linked to academic performance (Poropat, 2009). In our study, openness to experience negatively relates to GPA and this might be explained by the fact that the study was conducted in a vocational university, which emphasizes practical skills over abstract knowledge.

In line with past research, we also found that (passive) procrastination is detrimental to students’ GPA (Kim \& Seo, 2015; Steel et al., 2001). However, when students deliberately decide to procrastinate, it enhances their academic performance. In particular, students who voluntarily procrastinate and prefer to work under time constraints perform well scholastically. In both types of procrastination, individuals exercise the discretion to delay the course of action, but active procrastinators expect to achieve their objectives while passive procrastinators expect to be worse off due to this delay. Hence, our study demonstrates that passive and active procrastination are distinct constructs that uniquely predict academic performance. Past research showed mixed findings regarding the relationship between active 
procrastination and academic performance (Chu \& Choi, 2005; Choi \& Moran, 2009). Yet, these studies suffered from the fact that GPA was only reported by the participants themselves (Kuncel, Credé, \& Thomas, 2005). Our study shows that active procrastination has a significant impact on GPA when it is an objective measure obtained through the administration.

Insert Table 3

This study is not without limitations. First, the big five and procrastination measures are self-reports. While research has shown that self-reports are a relevant method with which to assess behavior, subsequent research should seek to assess these dimensions on a behavioral basis (Podsakoff, MacKenzie, Lee \& Podsakoff, 2003). A second limitation is that GPA and the procrastination scales were obtained at the same time. Hence, it is uncertain if we would observe the same relationship in a predictive design study in which the procrastination scales are administered before GPA data is collected. In order to further enhance our knowledge of different types of procrastination, future research should test the nomological network of procrastination in professional settings by examining which personality traits relate to passive and active procrastination and the extent to which the latter is linked to job performance. 


\section{References}

Alexander, E. S., \& Onwuegbuzie, A. J. (2007). Academic procrastination and the role of hope as a coping strategy. Personality and Individual Differences, 42, 1301-1310. doi:10.1016/j.paid.2006.10.008

Beswick, G., \& Mann, L. (1994). State orientation and procrastination. In J. Kuhl, \& J. Beckmann (Eds.), Volition and personality: Action versus state orientation (pp. 391-396). Gottingen, Germany: Hogrefe \& Huber.

Choi, J. N., \& Moran, S. V. (2009). Why not procrastinate? Development and validation of a new active procrastination scale. The Journal of Social Psychology, 149, 195-211. doi:10.3200/socp.149.2.195-212

Chu, A. H., \& Choi, J. N. (2005). Rethinking procrastination: Positive effects of "active" procrastination behavior on attitudes and performance. The Journal of Social Psychology, 145, 245-264. doi:10.3200/socp.145.3.245-264

DeSimone, P. (1993). Linguistic assumptions in scientific language. Contemporary Psychodynamics: Theory, Research and Application, 1, 8-17.

Ellis, A., \& Knaus, W. J. (1977). Overcoming procrastination: Or how to think and act rationally in spite of life's inevitable hassles. New York: Institute for Rational Living.

Ferrari, J. R. (1993). Christmas and procrastination: Explaining lack of diligence at a "realworld” task deadline. Personality and Individual Differences, 14(1), 25-33. doi:10.1016/01918869(93)90171-x

Ferrari, J. R., Johnson, J., \& McCown, W. G. (1995). Procrastination and task avoidance: Theory, research, and treatment. New York: Plenum Press.

Goldberg, L. R. (1999). A broad-bandwidth, public domain, personality inventory measuring the lower-level facets of several five-factor models. Personality Psychology in Europe, 7(1), 7-28.

Goldberg, L. R., Johnson, J. A., Eber, H. W., Hogan, R., Ashton, M. C., Cloninger, C. R., \& Gough, H. G. (2006). The international personality item pool and the future of public-domain personality measures. Journal of Research in Personality, 40(1), 84-96. doi:10.1016/j.jrp.2005.08.007

Howell, A. J., \& Watson, D. C. (2007). Procrastination: Associations with achievement goal orientation and learning strategies. Personality and Individual Differences, 43(1), 167-178. doi:10.1016/j.paid.2006.11.017

Johnson, J. L., \& Bloom, A. (1995). An analysis of the contribution of the five factors of personality to variance in academic procrastination. Personality and Individual Differences, 18(1), 127-133. doi:10.1016/0191-8869(94)00109-6 
Kim, K. R., \& Seo, E. H. (2015). The relationship between procrastination and academic performance: A meta-analysis. Personality and Individual Differences, 82, 26-33. doi:10.1016/j.paid.2015.02.038

Kuncel, N. R., Credé, M., \& Thomas, L. L. (2005). The validity of self-reported grade point averages, class ranks, and test scores: A meta-analysis and review of the literature. Review of Educational Research, 75(1), 63-82. doi: 10.3102/00346543075001063

Lay, C. H. (1995). Trait procrastination, agitation, dejection, and self-discrepancy. In J.R. Ferrari, I. L. Johnson, \& W. G. McCown. (Eds), Procrastination and Task Avoidance: Theory, Research and Treatment (pp. 97-112). New York: Plenum Press.

Lay, C., \& Silverman, S. (1996). Trait procrastination, anxiety, and dilatory behavior. Personality and Individual Differences, 21(1), 61-67. doi:10.1016/0191-8869(96)00038-4

Mccrae, R. R., \& Costa, P. T. (1997). Personality trait structure as a human universal. American Psychologist, 52, 509-516. doi:10.1037/0003-066x.52.5.509

Milgram, N. A., Batori, G., \& Mowrer, D. (1993). Correlates of academic procrastination. Journal of School Psychology, 31, 487-500. doi:10.1016/0022-4405(93)90033-f

Podsakoff, P. M., MacKenzie, S. B., Lee, J. Y., \& Podsakoff, N. P. (2003). Common method biases in behavioral research: a critical review of the literature and recommended remedies. Journal of Applied Psychology, 88(5), 879-903. doi: 10.1037/0021-9010.88.5.879

Poropat, A. E. (2009). A meta-analysis of the five-factor model of personality and academic performance. Psychological Bulletin, 135(2), 322-338. doi: 10.1037/a0014996

Pychyl, T. A. (2009). Active procrastination: Thoughts on oxymorons. Psychology Today. Retrieved from https://www.psychologytoday.com/blog/dont-delay/200907/activeprocrastination-thoughts-oxymorons Last accessed on March 22, 2016.

Roig, M., \& Detommaso, L. (1995). Are college cheating and plagiarism related to academic procrastination? Psychological Reports, 77, 691-698. doi:10.2466/pr0.1995.77.2.691

Schouwenburg, H. C., \& Lay, C. H. (1995). Trait procrastination and the Big-five factors of personality. Personality and Individual Differences, 18, 481-490. doi:10.1016/01918869(94)00176-s

Silver, M., \& Sabini, J. (1981). Procrastinating. Journal for the Theory of Social Behaviour, 11, 207-221. doi:10.1111/j.1468-5914.1981.tb00033.x

Steel, P. (2007). The nature of procrastination: A meta-analytic and theoretical review of quintessential self-regulatory failure. Psychological Bulletin, 133(1), 65-94.

doi:10.1037/0033-2909.133.1.65

Steel, P., Brothen, T., \& Wambach, C. (2001). Procrastination and personality, performance, and mood. Personality and Individual Differences, 30(1), 95-106. doi:10.1016/S01918869(00)00013-1 
Solomon, L. J., \& Rothblum, E. D. (1984). Academic procrastination: Frequency and cognitive-behavioral correlates. Journal of Counseling Psychology, 31, 503-509.

doi:10.1037//0022-0167.31.4.503

Tuckman, B. W. (1991). The development and concurrent validity of the procrastination scale. Educational and Psychological Measurement, 51, 473-480.

doi:10.1177/0013164491512022

Watson, D. C. (2001). Procrastination and the five-factor model: A facet level analysis.

Personality and Individual Differences, 30(1), 149-158. doi:10.1016/s0191-8869(00)00019-2 
Figure 1

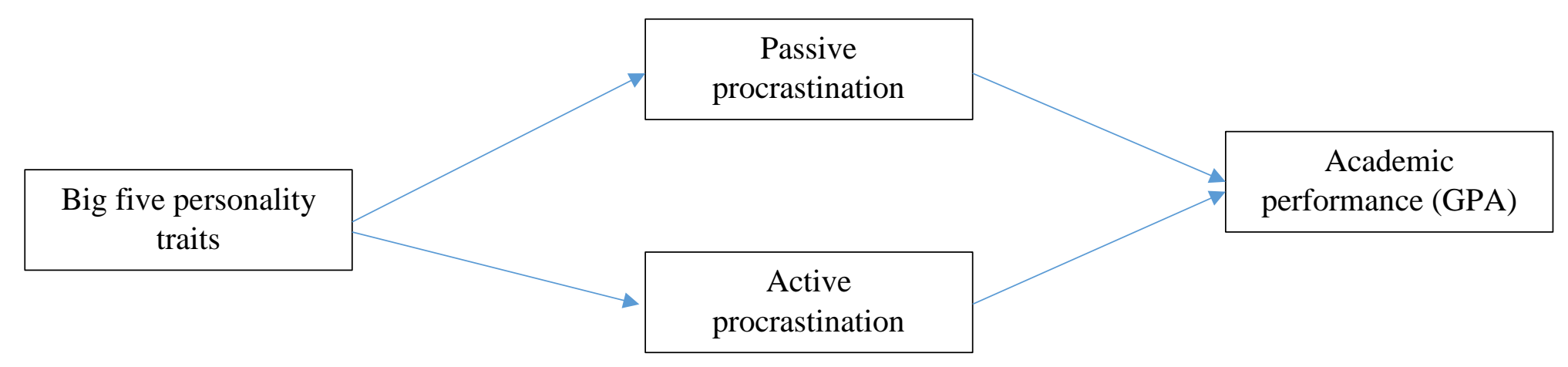


Table 1. Descriptive statistics and correlations.

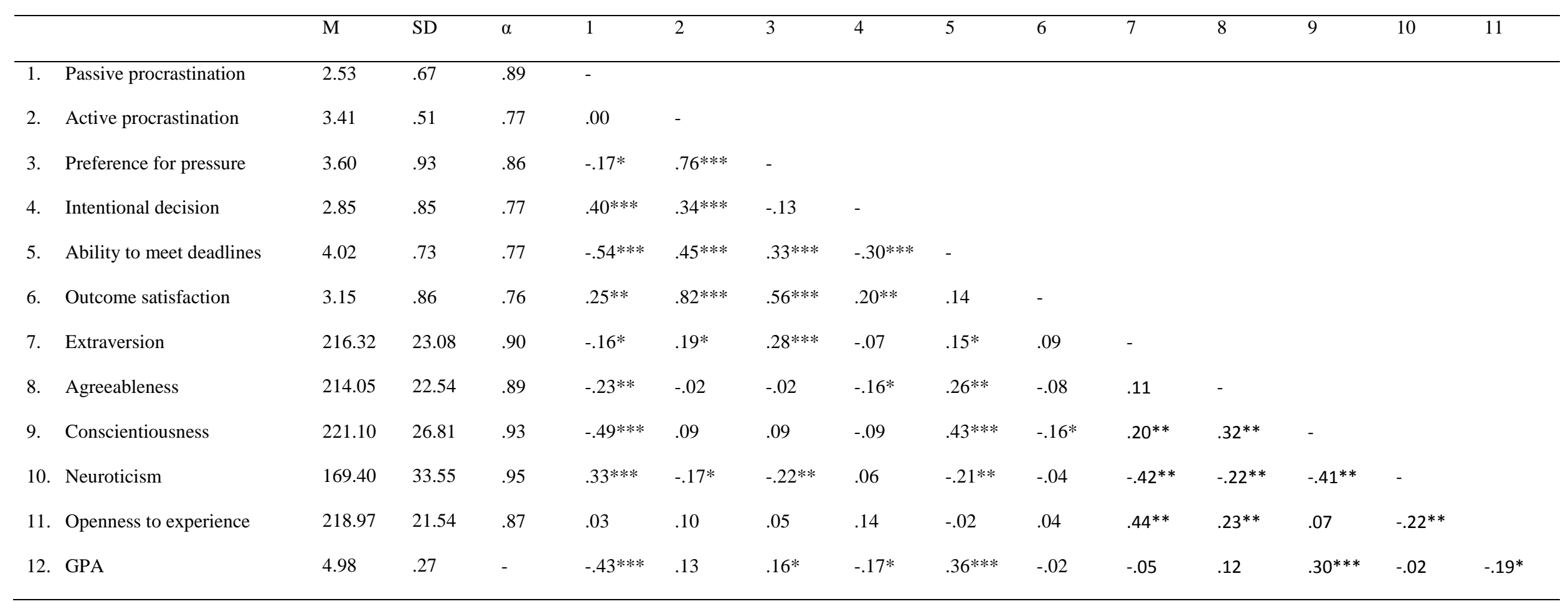

Note. ${ }^{*} \mathrm{p}<.05$, two-tailed; ${ }^{* *} \mathrm{p}<.01$, two-tailed; ${ }^{* * *} \mathrm{p}<.001$, two-tailed 
Table 2. Correlations between Big Five personality facets and the active procrastination scale and sub dimensions

\begin{tabular}{|c|c|c|c|c|c|}
\hline & $\begin{array}{c}\text { Active } \\
\text { procrastination }\end{array}$ & $\begin{array}{l}\text { Preference for } \\
\text { pressure }\end{array}$ & $\begin{array}{c}\text { Intentional } \\
\text { decision }\end{array}$ & $\begin{array}{c}\text { Ability to meet } \\
\text { deadlines }\end{array}$ & $\begin{array}{c}\text { Outcome } \\
\text { satisfaction }\end{array}$ \\
\hline Fantasy & -.08 & -.09 & .13 & $-.20 * *$ & -.07 \\
\hline Aesthetics & .00 & -.07 & .14 & -.06 & -.01 \\
\hline Feelings & .11 & .01 & .08 & .10 & .07 \\
\hline Actions & $.16^{*}$ & $.21^{* *}$ & -.04 & .09 & .10 \\
\hline Ideas & $.20 * *$ & $.17^{*}$ & .10 & .11 & .09 \\
\hline Values & .00 & -.02 & .10 & -.07 & -.02 \\
\hline Competence & $.26^{* * *}$ & $.29 * * *$ & -.03 & $.30 * * *$ & .06 \\
\hline Order & -.11 & $-.16^{*}$ & -.07 & $.29 * * *$ & $-.27 * * *$ \\
\hline Dutifulness & .02 & .00 & -.09 & $.33 * * *$ & $-.16^{*}$ \\
\hline Achievement striving & $.16^{*}$ & $.18 *$ & -.07 & $.35^{* * *}$ & -.05 \\
\hline Self-discipline & .07 & .14 & $-.17^{*}$ & $.42 * * *$ & $-.16^{*}$ \\
\hline Deliberation & .07 & .03 & .04 & $.21 * *$ & -.08 \\
\hline Warmth & $.16^{*}$ & $.19 *$ & -.08 & $.23^{* *}$ & .05 \\
\hline Gregariousness & .05 & $.17^{*}$ & -.12 & -.01 & .05 \\
\hline Assertiveness & $.25^{* *}$ & $.30 * * *$ & .01 & $.17^{*}$ & .11 \\
\hline Activity & $.24 * *$ & $.33 * * *$ & -.14 & $.33 * * *$ & .05 \\
\hline Excitement-seeking & .03 & .05 & .07 & -.14 & .05 \\
\hline Positive emotions & .06 & .09 & -.03 & .07 & .02 \\
\hline Trust & -.01 & .03 & -.13 & .06 & .04 \\
\hline Straightforwardness & -.02 & -.07 & -.11 & $.30 * * *$ & -.12 \\
\hline Altruism & .12 & .12 & -.06 & $.22 * *$ & .01 \\
\hline Compliance & -.03 & -.07 & -.11 & $.20^{* *}$ & -.05 \\
\hline Modesty & -.05 & -.04 & -.06 & .09 & -.10 \\
\hline Tender-mindedness & -.04 & .00 & -.14 & $.17^{*}$ & .09 \\
\hline Anxiety & $-.20 * *$ & $-.27 * * *$ & .04 & -.13 & -.10 \\
\hline Angry/hostility & -.08 & -.08 & .11 & $-.25^{* *}$ & .01 \\
\hline Depression & -.14 & $-.17^{*}$ & .08 & $-.20 * *$ & -.05 \\
\hline Self-consciousness & $-.16^{*}$ & $-.24^{* *}$ & .07 & $-.15^{*}$ & -.06 \\
\hline Impulsiveness & .03 & .05 & -.05 & -.12 & $.16^{*}$ \\
\hline Vulnerability & $-.23 * *$ & $-.33 * * *$ & .03 & -.09 & -.14 \\
\hline
\end{tabular}


Table 3. Hierarchical regression analyses of the Big Five factors, passive and active procrastination predicting GPA

\begin{tabular}{|c|c|c|c|c|}
\hline & \multicolumn{4}{|c|}{ GPA } \\
\hline & Step 1 & Step 2 & Step 3 & Step 4 \\
\hline Gender & .01 & .01 & .00 & -.01 \\
\hline Age & -.13 & -.12 & -.13 & $-.14 *$ \\
\hline$\Delta \mathrm{R}^{2}$ & .02 & & & \\
\hline Openness to experience & & $-.20 *$ & -.14 & -.15 \\
\hline Conscientiousness & & $.32 * *$ & $.16^{*}$ & .15 \\
\hline Extraversion & & -.01 & -.04 & -.06 \\
\hline Agreeableness & & .09 & .05 & .06 \\
\hline Neuroticism & & .07 & .12 & .14 \\
\hline$\Delta \mathrm{R}^{2}$ & & $.14 * * *$ & & \\
\hline Passive procrastination & & & $-.39 * * *$ & $-.40 * * *$ \\
\hline$\Delta \mathrm{R}^{2}$ & & & $.11^{* * *}$ & \\
\hline Active procrastination & & & & $.17 *$ \\
\hline$\Delta \mathrm{R}^{2}$ & & & & $.03 *$ \\
\hline
\end{tabular}

Note. ${ }^{*} \mathrm{p}<.05$, two-tailed. ${ }^{* *} \mathrm{p}<.01$, two-tailed 